\title{
Análise das mediações em ambientes de interação nas pesquisas na internet: uma proposta metodológica
}

\section{Ronei Teodoro da Silva}

Doutor; Universidade de Caxias do Sul; Caxias do Sul, RS, Brasil roneit@outlook.com

\section{Resumo}

Nas últimas décadas, diversos pesquisadores interessaram-se em investigar os fenômenos da recepção e o consumo de informações presentes nas interações entre sujeitos na internet. No entanto, é possível observar dificuldades de se associar questões culturais às tecnológicas ou, ainda, a necessidade de uma aproximação entre teorias sobre cultura, política e comunicação às mais centradas no ambiente virtual. Diante de tal cenário, propomos, nesse artigo, uma abordagem metodológica que combine a Análise de Redes Sociais ao Mapa das Mediações, como forma de combinar tradições metodológicas diferentes a fim de investigar um objeto comum aos dois campos. Tal estratégia foi elaborada e aplicada na tese de doutoramento que serviu de base para este artigo. 0 objetivo era conhecer as mediações que configuram as relações entre as lógicas de produção e as práticas de crítica de filmes no YouTube.

\section{Palavras-chave}

Mediações. Internet. Metodologia. Comunicação. Interação.

\section{Introdução}

De acordo com Knewitz (2010), é possível observar a dificuldade que diversos pesquisadores têm de aliar a temática da cultura à da tecnologia. Para a autora, os trabalhos com foco maior nos Estudos Culturais se dedicam mais a investigar as práticas sociais do que a analisar as plataformas e os dispositivos digitais, enquanto as pesquisas do campo cibercultural acabam não dando a devida atenção ao contexto socioeconômico e cultural dos processos comunicacionais. Scolari (2008) também já havia assinalado esse problema, 
afirmando não haver uma aproximação das teorias da Comunicação às totalmente focadas no mundo virtual. Em outras palavras, embora as pesquisas dos Estudos Culturais e Ciberculturais produzam investigações empiricamente próximas, ainda é possível verificar uma falta de aproximação das expertises de cada campo. Um dos grandes desafios dos trabalhos que se aventuram a estudar a noção de sentido no ambiente da internet seria promover a aproximação dessas duas abordagens.

Os Estudos Ciberculturais teorizam, por exemplo, sobre diversos tópicos que relacionam as práticas sociais aos processos de comunicação na internet, principalmente no que se refere à convergência das mídias, à transformação e às tendências dos meios tecnológicos e ao fluxo de informações em rede (SANTAELLA, 2010). Todos esses tensionamentos produziram grandes avanços para o campo científico, porém ocorreram sem um maior aprofundamento sobre o conceito da mediação. Ao termo, nesse campo de estudo, é correntemente atribuída à noção de interação intermediada, numa lógica epistemológica behaviorista de estímulos e respostas. Essa visão, contudo, é dependente de um modo tecnicista de ver a realidade. Outro sentido usualmente atribuído é o de meio, uma espécie de enfoque condutivista da informação, onde o computador e/ou a internet assumem puramente o papel de mídia.

É importante ressaltar que, de modo geral, essas pesquisas não têm como objetivo complexificar o termo mediação, tampouco se aprofundar em questões culturais e comportamentais (no sentido de analisar as competências de consumo e recepção de um determinado público). Por isso, seria imprudente julgá-las por não abordarem o conceito de maneira mais profunda. Pelo contrário, as contribuições desses autores foram fundamentais para o entendimento de diversos fenômenos dos Estudos Ciberculturais.

A discussão que trazermos aqui é algo já apontado por alguns autores do campo (SIGNATES, 2003; DAVALLON, 2007), que defendem haver uma lacuna de pesquisa que ainda pode ser explorada. A questão da mediação parece ser algo central nos Estudos Ciberculturais - como por exemplo, a própria denominação de uma das áreas, chamada de Comunicação Mediada pelo Computador - e, portanto, complexificá-la seria algo benéfico para o campo como um todo.

De acordo com Lopes, a contribuição distintiva da teoria latino-americana sobre mediações poderia ultrapassar abordagens teóricas fragmentadas e simplificadas como essa, “[...] posicionando as mediações como uma perspectiva teórica integrada da produção, produto e audiência dentro dos estudos comunicacionais." (LOPES, 2014, p. 66). Segundo a 
autora, a tradição latino-americana existe desde a década de 1980, quando um forte movimento teórico crítico procurou fazer uma reflexão alternativa sobre a comunicação e a cultura de massas, propondo um contraponto às análises funcionalistas, semióticas e frankfurtianas.

Lopes (2014) acredita que a tradição dos Estudos Culturais na América Latina coloca a relação político/cultural no centro de suas discussões, enquanto a perspectiva britânica Hoggart, Thompson e Williams - propõe que as práticas de recepção sejam articuladas com as relações de poder. Para a autora, ao analisarmos as práticas sociais da recepção sob a luz da política e da cultura, as veremos como parte integrante do processo, articulando questões tanto do ambiente imediato controlado pelo sujeito quanto da estrutura social que escapa a esse controle.

Para Martín-Barbero e Muñoz (1992), as mediações são uma forma de entender a interação entre o espaço de produção e o da recepção. Para os autores, o que é veiculado na mídia não responde unicamente aos interesses econômicos da indústria, mas também às exigências provenientes da trama cultural e daquilo que as pessoas desejam ver.

Silverstone (2002) expressa que devemos pensar os estudos de mídia como um processo de mediação. 0 autor defende ser necessário perceber que a mídia se estende para além das produções midiáticas ou da análise simples do consumo e recepção. Devemos considerar as relações entre os diferentes polos da sociedade, que estão condicionados às mediações.

Nesse sentido, esse artigo tem como objetivo apresentar aos pesquisadores que desejam investigar as interações humanas presentes na internet, uma proposta metodológica que leve em consideração questões culturais e tecnológicas. Tanto trabalhos que se dedicam a estudar as práticas sociais e culturais, quanto aqueles que se preocupam mais com o estudo da tecnologia e do ambiente virtual, podem se beneficiar ao relacionarem os conhecimentos específicos de cada campo.

\section{Contextualizando os procedimentos metodológicos}

Sugerir uma proposta metodológica integradora é algo extremamente desafiador, pois requer entendimento, interpretação e domínio do modus operandi de tradições metodológicas distintas. Para tanto, começamos com o levantamento bibliográfico amplo sobre metodologia na área da comunicação. Logo no início, encontramos disparidades e concordâncias em vários aspectos de como organizar uma pesquisa acadêmica. Dessa forma, 
optamos por usar aquilo que julgamos serem consensos entre a maioria dos autores (LOPES, 1990; SANTAELLA, 2001; BARROS; JUNQUEIRA, 2005; AZURDUY, 2007; MARCONI; LAKATOS, 2009): cada objetivo específico, ao mesmo tempo que deriva do geral, deve direcionar as ações metodológicas. Essa simples definição guiou toda a estruturação da proposta, especialmente no que diz respeito a como montar uma abordagem para um problema de pesquisa multidisciplinar de modo a usufruir as especificidades de cada campo.

Sendo assim, operacionalizamos os procedimentos seguindo a seguinte lógica: primeiro, identificamos a organização da informação e a forma como a interação era proposta pelo sistema; depois, verificamos os usos e apropriações que os interagentes faziam dessas possibilidades de interação; e, por último, analisamos a configuração das mediações neste ambiente. A primeira etapa foi iniciada pelo mapeamento e coleta de dados, identificando os diferentes tipos de interagentes e formas de participação, por meio da classificação de nós e conexões. Os passos dessa etapa foram estruturados a partir das orientações definidas no método de Análise de Redes Sociais (ARS). Na sequência, evidenciamos as potencialidades de comunicação, colaboração e disseminação dos conteúdos, combinando as técnicas da ARS e teoria das mediações dos Estudos Culturais. Por fim, averiguamos mais profundamente as mediações que configuravam o ambiente estudado a partir da aplicação do Mapa das Mediações (MARTÍN-BARBERO, 2013).

Embora tal abordagem metodológica pareça ser, em um primeiro momento, restrita apenas às pesquisas que desejam abordar o fenômeno da mediação na comunicação entre interagentes na internet, mostraremos adiante, como diferentes propostas podem usufruir desse método a fim de elaborarem seus procedimentos de coleta e análise de dados.

\section{Tecnologia e cultura: uma proposta metodológica integradora}

Para começar, sugerimos a divisão dos procedimentos metodológicos em duas fases. A fase 1 é composta pelo mapeamento da estrutura, a partir da identificação de conexões e nós ${ }^{1}$ do sistema e o fluxo de informações. Já a fase 2 é constituída das estratégias teóricas e dos procedimentos operacionais que determinam a avaliação das mediações.

\footnotetext{
${ }^{1}$ Fragoso, Recuero e Amaral (2012) apresentam um levantamento e problematizam estudos de ARS que conceituam e buscam entender as relações entre nós e conexões.
} 


\subsection{Fase 1: conhecendo a estrutura e o fluxo de informações}

Fragoso, Recuero e Amaral (2012) afirmam que a ARS deve ser iniciada a partir de uma série de delimitações. Por sua complexidade, antes de captar e interpretar os dados, devemos entender a estrutura e a forma como o fluxo de informações transcorre no sistema estudado. Para tanto, dividimos essa fase em 3 etapas.

\subsubsection{Etapa 1, determinando a organização da estrutura e dos tipos de conteúdo}

De acordo com as autoras, as redes sociais na internet podem assumir duas características diferentes com relação à organização da estrutura: redes emergentes ou de filiação. As emergentes são aquelas mantidas pela interação entre os nós enquanto as de filiação, pelo sistema. No primeiro caso, o ator social tem um papel mais ativo, no qual a interação depende da sua iniciativa para acontecer. No segundo caso, o próprio sistema organiza essa interação, transformando-a em um feed de notícias onde as conexões são organizadas de acordo com o perfil do usuário.

Conforme observamos em trabalhos como os de Pieniz (2013), Aquino (2012) e Knewitz (2010), o tipo e a formato dos conteúdos publicados em uma rede na internet dependem dos usos e apropriações que os usuários fazem do sistema. Uma rede pode assumir diferentes funções, de acordo com o tipo de conteúdo publicado. Entre as possibilidades, podemos destacar os papéis de um veículo de comunicação, virtual settlement, fórum de discussão e rede social. Já os formatos podem ser amador ou profissional, com conteúdos informativos ou de entretenimento.

Para determinar o tipo de rede e disposição do conteúdo, sugerimos como estratégia metodológica a meta-pesquisa (NAVARRO, 2007). Por meio desse método, é possível entender e contextualizar as ações anteriores que resultam na disposição da estrutura e nas diferentes funções atribuídas às redes sociais na internet. Porém, quando os trabalhos não fornecem dados suficientes, sugerimos a exploração retroativa de dados. Nesse sentido, o próprio sistema pode oferecer formas de buscar publicações mais antigas. Por meio delas, torna-se viável o mapeamento cronológico do conjunto de ações que estabeleceram a disposição atual do sistema. Nas ocasiões em que isso não é possível, recomendamos como instrumento de coleta o site Internet Archive Wayback Machine. Trata-se de uma iniciativa privada na web, mantida por doações, que tem como objetivo registrar a produção na internet. 0 site faz uma varredura por diversas páginas na internet, capturando-as e 
guardando em um arquivo disponível ao público para pesquisa. É possível consultar dados a partir de 1996, ano que começaram a registrar as atividades na web. Para se ter uma dimensão do tamanho da coleção, quando alcançou cinco anos de coleta, o arquivo já mantinha mais de 100 terabytes de conteúdo (INTERNET ARCHIVE WAYBACK MACHINE, 2016).

A navegação pelas páginas antigas dos sites oferece pistas como a data de um evento relevante, o nome de uma empresa ou uma nova página a ser consultada. De acordo com os achados, é possível traçar os passos seguintes, sejam eles realizar novas buscas no mecanismo ou investigar o conteúdo de uma determinada página.

\subsubsection{Etapa 2, classificação dos nós}

Fragoso, Recuero e Amaral (2012) aconselham definirmos o que consideraremos nós (compostos por indivíduos, instituições ou grupos) e conexões (constituídas pelos diferentes tipos de interação proporcionados pelo sistema, tais como comentários, hyperlinks, etc.). A ARS oferece algumas técnicas para esquematizar esse estágio. Por meio delas, é necessário traçar tanto a abrangência quanto as delimitações que se deseja ter. 0 primeiro passo é definir a estrutura e a classificação dos nós da rede. Para isso, indicamos os conceitos de densidade e centralidade. 0 primeiro se refere ao número de conexões ligadas a um nó, enquanto a segunda é observada pela proximidade das conexões, ou seja, a ausência de nós intermediários. Normalmente a centralidade é uma indicativa de popularidade.

Um nó pode ser mais ou menos denso. Quando muito denso, é chamado de hub, ou seja, um local com muitas conexões interligadas de forma centralizada. Já um conjunto de hubs forma um cluster. A uma rede com muitos hubs é atribuída a nomenclatura de rede clusterizada (FRAGOSO; RECUERO; AMARAL, 2012).

\subsubsection{Etapa 3, determinando os níveis de conexão}

A terceira etapa constitui em determinar os níveis de interação entre os nós, por meio dos graus de conexão. Quanto mais distante os nós estão um dos outros, maior o número de graus de conexão, conforme ilustrado na figura 1. 
Figura 1 - Graus de conexão

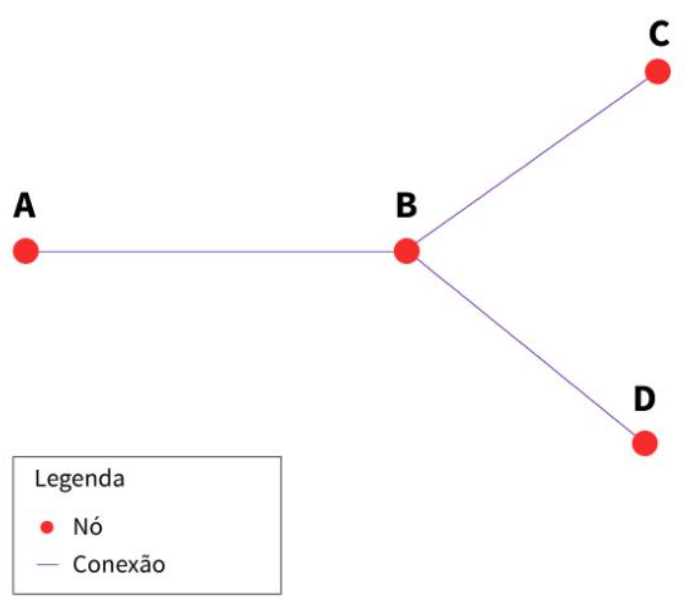

Fonte: Elaborado pelo autor.

$\mathrm{O}$ nó A possui conexão direta com o nó B, caracterizando grau um de conexão. $\mathrm{O}$ nó $\mathrm{B}$ está ligado aos nós C e D também por grau um de conexão. Nesse caso, o nó A está conectado aos $\mathrm{C}$ e $\mathrm{D}$ por meio do nó $\mathrm{B}$, porém a conexão é considerada de grau dois, por não ser direta.

A quantidade de graus que se deve avançar no sistema depende basicamente de duas variáveis. A primeira, se refere à potencialidade de interação. Se um nó tem poucas conexões de grau um, terá menos possibilidade de interagir ou de gerar interação. Quando isso ocorre, avançamos mais graus de conexão para obter uma quantidade maior de dados. A segunda, diz respeito à qualidade das interações, retratada na ARS como composição das conexões, medidas em laços fortes e fracos. Na prática, mesmo que um nó tenha muitas conexões ligadas a ele, isso não significa necessariamente que ocorra interação na mesma proporção. Um nó pode ser muito denso, ou seja, agrupar um grande número de conexões de grau um, porém, provavelmente por causa disso, não consiga manter uma reciprocidade de interação.

A potencialidade de interação pode ser medida de acordo as oportunidades de conexões que o sistema oferece. Essas oportunidades são definidas pelas conexões internas e externas. As internas são formadas pelas interações propiciadas dentro do site, enquanto as externas ocorrem fora do ambiente, mas têm impacto direto na estrutura e no fluxo de informações dele.

Para identificar as conexões internas e externas, recomendamos a observação de dados dinâmicos e processos emergentes, também sugeridos pela ARS. Os dados dinâmicos referem-se às consequências diretas da interação entre os nós e são aferidas de acordo com 
os processos emergentes de uma rede social. São processos denominados emergentes aqueles comportamentos que ampliam a estrutura inicial proporcionada pela rede, tais como a cooperação, a adaptação, a auto-organização e o aparecimento de mundos pequenos ${ }^{2}$. Ou seja, determina-se as potencialidades de interação de acordo com a formação de conexões internas e externas que, por sua vez, são estipuladas pela forma como os interagentes usam e se apropriam dos recursos do sistema.

Após definição das potencialidades, propomos observar a variável qualidade das interações. É importante ressaltarmos que estabelecer a força dos laços sociais presentes em uma rede depende do conhecimento que temos sobre a configuração da mesma. A melhor forma de fazer isso é seguindo a abordagem de rede ego (FRAGOSO; RECUERO; AMARAL 2012). Por ela, traçamos as conexões partindo de um ponto inicial e seguindo as possibilidades de interações exponencialmente, de acordo com seu fluxo. Essa técnica é comumente usada quando não se conhece o que motiva as interações entre as conexões.

A força dos laços sociais de uma rede, que determina o fluxo das interações, é normalmente definida pelo capital social. Esse conceito pode ser separado em diversas categorias, mas é na sua definição mais ampla que acreditamos ser útil para essa etapa da metodologia. Vimos que, apesar de haver discordância entre alguns teóricos (COLEMAN, 1988; PUTNAM, 2000; BERTOLINI; BRAVO, 2002), a ideia de valor é algo recorrente. De um modo geral, os estudiosos da área entendem o capital social como produto do pertencer a um grupo (rede) de atores e aqueles valores que dali decorrem. Ou seja, as pessoas mantêm os laços de conexão fortes ou fracos de acordo com o valor social percebido em manter essas relações.

Dessa forma, a popularidade de um nó indica que os outros encontram nele uma produção que vale a conexão. Embora um hub não consiga manter reciprocidade de interação, ele pode se beneficiar monetizando seu espaço, exatamente pela atenção que consegue reunir. Para os seguidores de um $h u b$, o capital social está na capacidade desse em gerar conteúdo de qualidade, enquanto que para o hub, o capital social está no número de conexões.

De forma geral, essa estratégia nos permite entender a organização e o fluxo de informações e a formação de clusters e hubs dentro da estrutura do sistema. 0 uso desses

\footnotetext{
2 De acordo com Shirky (2009), redes de mundo pequeno são um tipo de grafo matemático nos quais grande parte das conexões são estabelecidas entre os vértices mais próximos, não havendo conexões longas entre os nós. São agrupamentos locais com laços fortes, formando assim pequenas comunidades dentro da rede.
} 
procedimentos nos fornece conteúdos importantes para a contextualização do ambiente, como dados sobre as lógicas da produção e consumo, os formatos industriais e as matrizes culturais (informações essenciais para a fase 2). Para facilitar o entendimento da fase 1, elaboramos um esquema (figura 2) que propicia a visualização, resumidamente, de cada etapa do processo.

Figura 2 - Esquema metodológico da fase 1

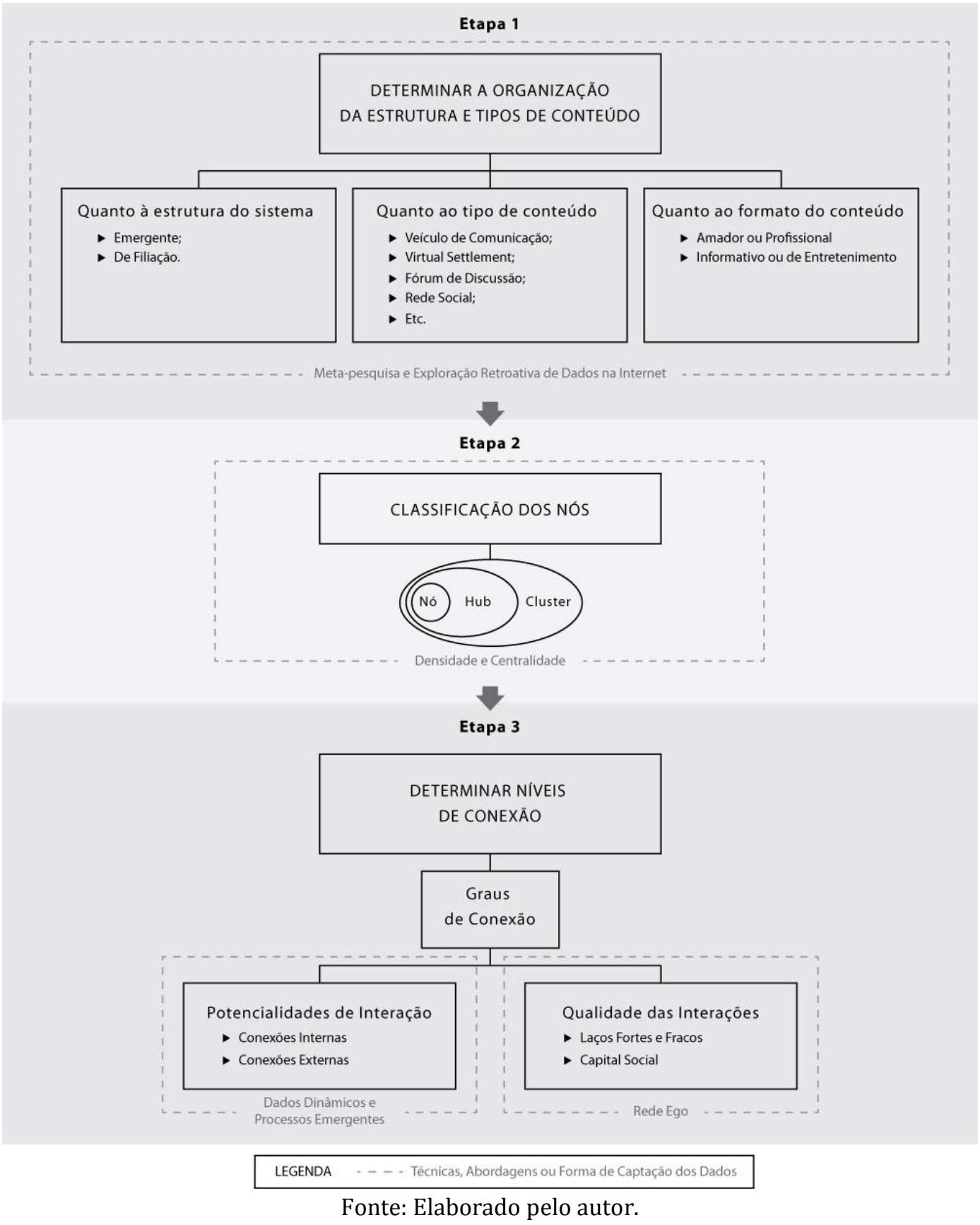




\subsection{Fase 2: estratégias teóricas e procedimentos de avaliação das mediações}

A obra Dos meios às mediações, de Martín-Barbero (2013) é considerada texto base no que se refere à teoria sobre mediações. 0 autor propôs que a comunicação seja estudada a partir de processos que a atravessam, nos locais onde se dá o embate entre o meio e a audiência, nos quais se estabelece a noção da realidade e a apropriação de sentidos. Para tanto, introduz a cotidianidade familiar, a temporalidade social e a competência cultural como instâncias mediadoras. De acordo com Orozco (1998), isso possibilitou que os conceitos e fenômenos pudessem ser investigados com base nas interferências que neles se manifestam, tornando-se construções relacionais, dinâmicas e negociadas, ao invés de serem entendidos como verdades absolutas, fixas e deterministas.

No prefácio de seu livro, Martín-Barbero (2013) incluiu um esquema que demonstra como o processo de comunicação se dá nas sociedades contemporâneas. Segundo Lopes (2014), trata-se de um mapa conceitual, ou mapa das mediações. De acordo com a autora, no final dos anos 1990, Martín-Barbero (2013) alterou o mapa original, publicado antes, pois percebeu que a teoria das mediações ultrapassava a configuração de uma teoria da recepção e alcançava a proposta de uma teoria da comunicação. Para Lopes (2014), o mapa barberiano deixou de ser um mapa da mediação cultural da comunicação para se tornar um mapa da mediação comunicativa da cultura, ao colocar o estudo da cultura a partir da comunicação. Na prática, se acrescentou uma maior densidade epistemológica, de forma a auxiliar a operacionalização da análise de qualquer fenômeno social que se relaciona com a comunicação, cultura e política. Acrescentaram-se as articulações entre os diferentes polos do processo.

O mapa das mediações (figura 3) é dividido em dois eixos principais: o diacrônico (deslocamento entre as Matrizes Culturais e os Formatos Industriais) e sincrônico (movimento entre as Lógicas de Produção e as Competências de Recepção - ou Consumo). As Matrizes Culturais concatenam a produção hegemônica da comunicação, de acordo com as transformações tecnológicas e os interesses capitais. Nos Formatos Industriais são identificadas as características discursivas, narrativas ou textuais e suas transformações em discursos, gêneros e programas. Nas Lógicas de produção está a preocupação com os interesses do Estado, políticos e econômicos; a regulação do mercado; e as demandas da recepção. Por fim, nos espaços das Competências de Recepção/Consumo encontram-se as práticas sociais que oportunizam a produção de sentido. 
Figura 3 - Mapa das mediações

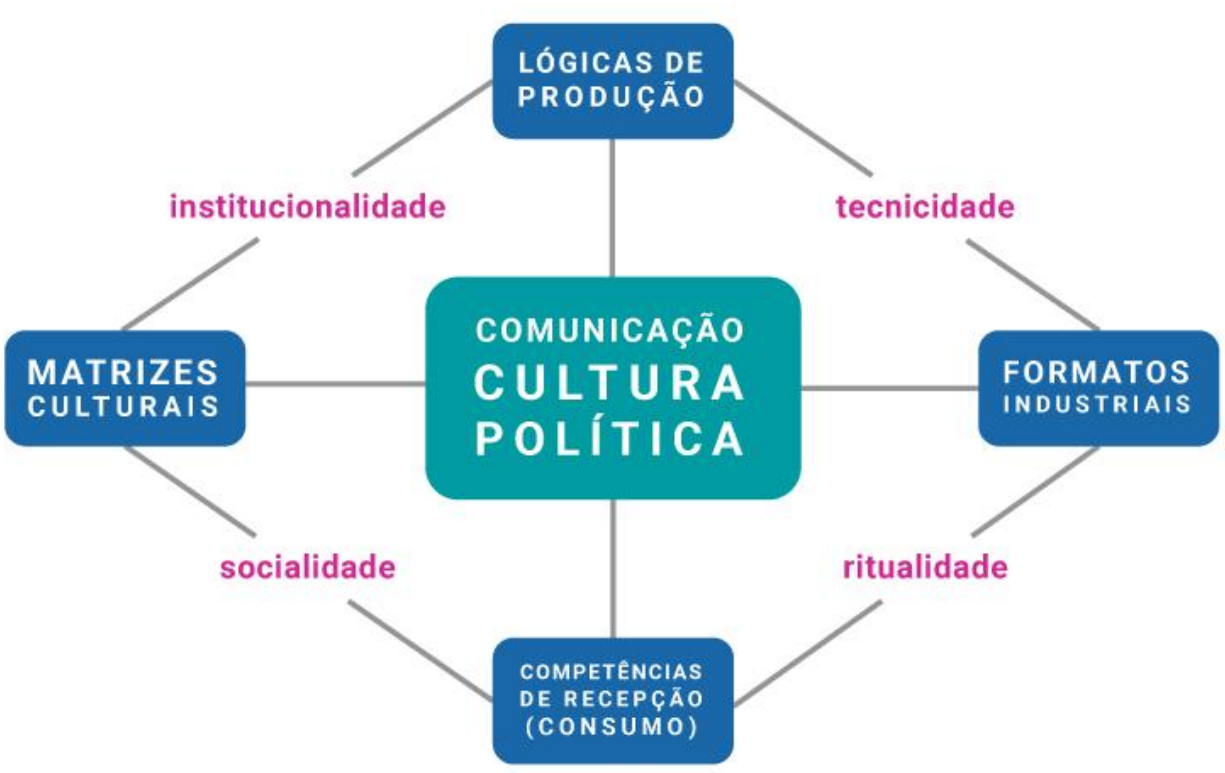

Fonte: Adaptado de Martín-Barbero (2013).

As relações existentes entre os polos são condicionadas pelas mediações comunicativas da cultura (JACKS, 2008), divididas entre socialidade, ritualidade, tecnicidade e institucionalidade. Para se investigar as mediações que configuram as complexas relações existentes nas interações ciberculturais, sugerimos definir um ponto de partida. MartínBarbero (2013) conceitua em detalhes cada polo do esquema, assim como as mediações acionadas de acordo com o deslocamento da informação, no eixo sincrônico e diacrônico. A decisão de onde se irá começar, quais pólos serão utilizados e em que extensão dependerá dos objetivos da pesquisa que se pretende fazer.

Para um estudo mais aprofundado, recomendamos escolher um polo e abordar os fenômenos de forma mais focada. Os estudos de recepção, principalmente aqueles centrados nas práticas de determinado público, podem, por exemplo, organizar seu corpus a partir da configuração da socialidade e ritualidade. Já, os estudos mais delimitados na produção de significados, podem construir sua interpelação mais pelos vieses da tecnicidade e institucionalidade. Quanto mais específico o público/produção que se deseja investigar, maior a necessidade de se acrescentar etapas aos procedimentos, possivelmente incluindo métodos como entrevista, netnografia e/ou grupos focais. 
É possível, também, fazer uma aplicação completa do mapa. Tal estratégia foi usada na tese que serviu de base para esse artigo (SILVA, 2017). Essa abordagem permite uma visão geral da situação, mas impossibilita aprofundamento em questões específicas. Isso não significa que os resultados produzidos serão superficiais, pelo contrário, essa escolha auxilia a refletir sobre a perspectiva cultural e tecnológica de uma maneira ampla e integradora. Como dissemos, as escolhas dependerão dos propósitos de cada investigação e elas definirão o uso que se pode fazer do mapa das mediações.

A socialidade se estabelece no cotidiano, vinculando à tradição cultural e ao modo como os receptores relacionam-se com a cultura massiva. Essa categoria permite analisar o cenário em que a subjetividade e as identidades são construídas, as vinculações dos indivíduos com o mundo social. Segundo Jacks (2008, p. 22), a socialidade figura “[...] como um almálgama que vincula a tradição cultural com o modo de os receptores relacionarem-se com a cultura massiva". Ou seja, devemos levar em conta a tradição do consumo de entretenimento presentes na cultura - Matrizes Culturais - associando as interações promovidas no sistema. Segundo Martín-Barbero (2013), a socialidade permite a análise do contexto onde os receptores atuam e/ou movimentam-se. Como teoria de apoio, recomendamos a relação desta mediação ao conceito de socializações, proposto por Berger e Luckmann (1985). Para os autores, a forma como damos sentido ao mundo é algo instituído ao longo da vida por família, escola, igreja e comunidades.

Tal noção auxilia a refletir sobre a perspectiva cultural, isto é, como a relação entre audiência e conteúdo depende do contexto social. A visão de mundo está imbricada aos aprendizados que recebemos ao longo de nossas vidas. Portanto, a realidade e os valores partem de algo socialmente compartilhado, de acordo com nosso convívio. Assim, problematizar a socialidade é algo fundamental nas reflexões sobre as práticas sociais.

A ritualidade media a relação da audiência com os meios, mobilizada pela memória dos receptores, a partir das suas socializações (BERGER; LUCKMANN, 1985) e dos formatos industriais utilizados pelos meios. Regula a interação entre as práticas da recepção a partir dos formatos da produção. A ritualidade reflete como as práticas são dependentes dos Formatos Industriais (que, por sua vez, são regulados pelos interesses da produção e anseios da recepção). Por suas características, a internet permite uma relação mais personalizada, de acordo com as possibilidades de cada ponta do eixo. Assim, a noção de assincronidade (REID, 1991) é muito importante para análise dessa mediação. 0 fato da relação de tempo entre emissão e consumo ser mais elástico nesse meio, dispensa a 
simultaneidade no processo de comunicação. Dessa forma, os rituais necessários, tanto para produzir quanto para consumir, adaptam-se às capacidades e motivações dos interagentes do sistema, algo que é passível de avaliação. Os hábitos são definidos de acordo com as possibilidades oferecidas pela tecnologia. Nesse sentido, a teoria de fluxo, superfluxo e fluxo da audiência, proposta por Jensen (2010), é de grande serventia, pois por meio dela, é possível decompor os ritos de acordo com cada ponta do sistema.

A tecnicidade relaciona as inovações inerentes ao campo da produção e o modo como elas afetam as linguagens midiáticas. Ao transformar o material discursivo e o ambiente onde ele ocorre, promove novas práticas sociais. Para Martín-Barbero (2013), a técnica ultrapassa a ordem instrumental, assentando os saberes e a constituição das práticas, o que torna visível a inovação presente nos Formatos Industriais. Sendo assim, tanto os discursos como as formas são afetados, além da própria percepção da recepção. Ao começar uma análise pelo viés da tecnicidade, acaba-se por abordar tanto as transformações materiais quanto as inovações discursivas.

No âmbito da produção, a tecnicidade afeta as decisões e a exploração comerciais de uma obra, pelo viés da convergência midiática. Para auxiliar a compreensão da configuração dessa mediação, sugerimos relaciona-la às seis tendências das comunicações digitais propostas pela Escola de Toronto $^{3}$ (PEREIRA, 2002). Essa associação nos ajuda a entender a tecnicidade como algo que conecta as inovações com as percepções e experiências sociais, ou seja, reconhecemos que há uma relação entre as inovações tecnológicas e os usos e apropriações das mesmas, de modo que cada novo produto midiático obedece tanto às lógicas e articulações do dispositivo para o qual foi criado quanto a forma como esse dispositivo é usado. Em outras palavras, as novas práticas estão condicionadas aos dispositivos tecnológicos, seja nas suas características materiais, seja nas funcionais. 0 aprimoramento tecnológico e técnico permite reconfigurar as possibilidades da recepção, criando, também, com isso, novas demandas. Sendo assim, aconselhamos também uma relação com as teorias de meios de terceiro grau de Jensen (2010), assimilação e reciclagem de McLuhan (2007) e de remediação, de Bolter e Grusin (1999), para tratar da relação entre inovações e experiências sociais presentes nessa mediação. Essas teorias nos auxiliam a verificar como as técnicas, formas e significados sociais de outros meios são reapropriados, de modo a adaptar o novo a aspectos culturais já estabelecidos.

\footnotetext{
${ }^{3}$ A Escola de Toronto, representada por Harold Innis, Eric Havelock e Marshall McLuhan, tinha como objetivo estudar como as tecnologias comunicacionais possuem um poder intrínseco de trasnformação das culturas e das subjetividades.
} 
Por fim, a institucionalidade refere-se à produção de discursos públicos que tendem a atender às lógicas hegemônicas dos interesses privados, mesmo que atuem sobre ideais contraditórios. Segundo Jacks, essa mediação “[...] surge para dar conta de uma forma mais concreta e específica do âmbito dos meios, ou seja, dos discursos públicos, carregados de interesses e poderes contraditórios, mas que tendem à homogeneidade." (JACKS, 2008, p. 21). A autora afirma que há regimes diferentes de institucionalidade, sendo afetada por ambos os contextos - o sincrônico, das lógicas de produção, e o diacrônico, das matrizes culturais - por meio do processo histórico-cultural.

A institucionalidade nos ajuda a perceber como duas ordens contrapostas (o regime estatal e o de mercado) se relacionam de forma a constituir um ambiente amplo de produção comunicacional. De forma geral, no estatal temos a regulação, pela criação de leis e abertura de concessão de meios de comunicação e, do lado mercadológico, empresas se constituem para converter a liberdade de expressão em veículos de comunicação, de modo a atender aos interesses econômicos dos investidores. Para Martín-Barbero (2013), ambos atuam de maneira simultânea, configurando o espaço público a partir da priorização de valores quase sempre antagônicos. 0 autor afirma que a institucionalidade afeta a regulação dos discursos tanto do Estado, que busca estabilidade e ordem contínua, quanto dos cidadãos, que reivindicam mudanças, de acordo com seus interesses. Temos, na institucionalidade, a produção de discursos públicos e privados que procuram manter uma hegemonia.

Mais uma vez, propomos relacionar uma mediação proposta no mapa barberiano à outra teoria, de modo a nos munirmos com mais possibilidades de análise dos fenômenos. Nesse sentido, propomos a associação das ideias de Martín-Barbero (2013) ao conceito de ideologia proposto por Thompson (1995). Para esse autor, estudar ideologia é entender as maneiras como o sentido serve para estabelecer e sustentar relações de dominação, mantendo, portanto, uma hegemonia de poder. Thompson (1995) estabelece cinco modos de operação da ideologia por essa ótica: legitimação, dissimulação, unificação, fragmentação e reificação. A legitimação, segundo o autor, diz respeito a um modo de operação, no qual as relações de dominação são estabelecidas e sustentadas pelo fato de serem representadas como legítimas, como justas e dignas de apoio. Na dissimulação, as relações de dominação são "ocultadas, negadas ou obscurecidas", representadas "de uma maneira que desvia nossa atenção" ou, ainda, não levam em conta relações e processos existentes (THOMPSON, 1995, p. 83). A unificação refere-se à construção, no nível simbólico, de uma forma de unidade que 
interliga os indivíduos em uma identidade coletiva, independentemente das diferenças e divisões que possam separá-los. A fragmentação trata da segmentação de indivíduos e grupos, de maneira a se contrapor às ideias que não lhes interessam. Por fim, a reificação envolve a eliminação ou ofuscação, do caráter sócio-histórico dos fenômenos, de modo a naturalizar os acontecimentos como algo previamente estabelecido, normalmente apoiando-se em costumes, tradições e instituições.

A aproximação entre as operações ideológicas e a mediação institucional auxilia a compreender a relação entre as Matrizes Culturais e as Lógicas de Produção. Assim como Martín-Barbero (2013), Thompson (1995) relaciona o poder com a cultura, de modo a manter a ordem social e hegemonia de classe. A reprodução das relações sociais está ligada aos valores e crenças socialmente compartilhados. Para Thompson (1995), podemos observar os elementos da ideologia dominante que, por estar difundida na sociedade, garante a adesão das pessoas à ordem social. 0 autor declara que a reprodução e difusão da ideologia é uma das tarefas do Estado e de interesses privados de uma classe dominante.

Quando observamos a mediação institucional sob a luz do conceito de ideologia proposto por Thompson (1995), podemos evidenciar a presença de discursos hegemônicos, de forma a reproduzir e atender os interesses privados e públicos. Nesse sentido, ambos os autores alertam para atentarmos a um cenário no qual, o que as pessoas leem, veem e ouvem é algo familiar e banal, e nessa esfera simbólica de familiaridade repetitiva é inserida uma cadeia de slogans aparentemente inocentes, que se apresentam como verdades autoevidentes e eternas. 0 processo de consumir produtos da indústria cultural, por exemplo, induziria as pessoas a identificarem-se com as normas sociais existentes e a continuarem a ser o que já são. Porém, conforme apontado por Thompson (1995), esse processo não é estável, havendo um contínuo conflito entre dominantes e dominados. Martín-Barbero (2013) representa esses tensionamentos no centro do mapa, mostrando que o processo comunicacional está condicionado a questões culturais e políticas.

Dessa forma, estruturamos a análise das mediações do mapa barberiano sempre a relacionando com outras teorias, sejam elas provenientes de uma tradição social ou cibercultural. Para facilitar a visualização das estratégias teóricas, apresentamos abaixo, no quadro 1 , um esquema com nossas escolhas. 
Quadro 1 - Associações teóricas para análise das mediações - Fase 2

\begin{tabular}{|c|c|}
\hline Mapa Barberiano & Teorias associadas \\
\hline Tecnicidade & $\begin{array}{l}\text { - Convergência midiática (JENKINS, 2007) } \\
\text { - Tendências das tecnologias de comunicação digital (PEREIRA, } \\
\text { 2002) } \\
\text { - 3o grau de comunicação (JENSEN, 2010) } \\
\text { - Assimilação e reciclagem (MCLUHAN, 2007) } \\
\text { - Remediação (BOLTER; GRUSIN, 1999) }\end{array}$ \\
\hline Ritualidade & $\begin{array}{l}\text { - Assincronidade (REID, 1991) } \\
\text { - Fluxo, superfluxo e fluxo da audiência (JENSEN, 2010) }\end{array}$ \\
\hline Socialidade & - Socializações (BERGER; LUCKMANN, 1985) \\
\hline Institucionalidade & - Ideologia (THOMPSON, 1995) \\
\hline
\end{tabular}

Fonte: Elaborado pelo autor.

\section{Considerações finais}

O caráter descentralizado da comunicação nesse ambiente torna desafiador o panorama para as investigações sobre comunicação na internet, pois as interações ocorrem em termos de redes, numa dinâmica integradora e colaborativa. A proposta metodológica apresentada nesse artigo sugere uma aproximação entre os conhecimentos produzidos pelos Estudos Culturais e os produzidos pelos Estudos Ciberculturais de forma integrada, já que essas perspectivas teóricas voltam seus esforços para compreensão de fenômenos similares. Ao incluirmos uma perspectiva multidimensional, que partilha influências com acontecimentos de outras esferas da sociedade, evitamos presunções que se assentam demasiadamente na cultura ou na tecnologia.

A articulação entre as duas as duas etapas dependerá dos objetivos de pesquisa. 0 caso que serviu de base para este artigo (SILVA, 2017), começa pelo mapeamento e coleta de dados, identificando os diferentes tipos de interagentes e as formas de participação na plataforma pesquisada (YouTube), por meio da classificação dos nós e conexões. Na sequência, foram evidenciadas as potencialidades de comunicação, colaboração e disseminação dos conteúdos, combinando as técnicas de ARS e a teoria das mediações dos 
Estudos Culturais. Por fim, foram averiguadas, mais profundamente, as mediações que configuravam o ambiente estudado a partir da aplicação do mapa barberiano.

Reconhecemos que a tentativa de aproximar algo tão complexo quanto a questão da mediação no ambiente online não pode ser "simplificada" em uma única abordagem metodológica. Esse não era nosso objetivo, tampouco tínhamos essa ambição. 0 que procuramos foi construir um ponto de intersecção, fundamental para uma visão menos unilateral, assim como defendido por Natansohn "[...] uma compreensão ampla do fenômeno dos usos, das leituras e do consumo da Web exige [...] aproximar tradições de pesquisa bastante diversas." (NATANSOHN, 2007, p. 3). Ao identificarmos o modo como as mediações operam, podemos compreender como o fluxo da comunicação exposto neste cenário reconfigura não apenas o consumo e a audiência, mas os próprios processos produtivos da indústria tecnológica. A incorporação da noção mediações comunicativas da cultura (MARTÍN-BARBERO, 2013) aos Estudos Ciberculturais possibilita um aproveitamento teórico-metodológico que, inevitavelmente, resultará em um avanço para ambas as áreas.

\section{Referências}

AQUINO, Maria Clara. Convergência entre televisão e web: proposta de categorização analítica. 2012. Tese (Doutorado em Comunicação e Informação) - Universidade Federal do Rio Grande do Sul, Porto Alegre, 2012.

AZURDUY, Carlos A. Camacho. Metodología de la investigación comunicacional: una aproximación desde el estudio del consumo cultural de la radio entre mujeres migrantes de la ciudad de El Ato. La Paz: Gugly XtraPubli, 2007.

BARROS, Antonio Teixeira; JUNQUEIRA, Rogério Diniz. A elaboração do projeto de pesquisa em comunicação. In: DUARTE, Jorge; BARROS, Antonio. (Org.). Métodos e técnicas de pesquisa em comunicação. São Paulo: Atlas, 2005.

BERGER, Peter; LUCKMANN, Thomas. A construção social da realidade: tratado de sociologia do conhecimento por Peter Berger e Thomas Luckmann. 13. ed. Petrópolis: Vozes, 1985.

BERTOLINI, Sonia; BRAVO, Giangiacomo. Social capital, a multidimensional concept. Exeter, 2002.

BOLTER, Jay David; GRUSIN, Richard. Remediation: understanding new media. Cambridge: MIT Press, 1999.

COLEMAN, James S. Social Capital and the creation of human capital. The American Journal of Sociology, Chicago, v. 94, p. S95-S120, 1988. 
DAVALLON, Jean. A mediação: a comunicação em processo? Prisma.com: revista de Ciências e Tecnologias de Informação e Comunicação, Porto, n. 4, 2007.

FRAGOSO, Suely; RECUERO, Raquel; AMARAL, Adriana. Métodos de pesquisa para internet. Porto Alegre: Sulina, 2012.

INTERNET ARCHIVE WAYBACK MACHINE. Frequently asked questions: the Wayback Machine. [2016].

JACKS, Nilda. Repensando os estudos de recepção: dois mapas para orientar o debate. Ilha: Revista de Antropologia, Florianópolis, v. 10, n. 2, 2008.

JENKINS, Henry. Nine propositions towards a cultural theory of youtube. Confessions of an Aca-fan: the official weblog of Henry Jenkins, Los Angeles, May 2007.

JENSEN, Klaus Bruhn. Media convergence: The three degrees of network, mass, and interpersonal communication. London: T\&F Books UK, 2010.

KNEWITZ, Ana Paula. A leitura jornalística na contemporaneidade: novas e velhas práticas dos leitores de zerohora.com. 2010. Dissertação (Mestrado em Comunicação e Informação) - Universidade Federal do Rio Grande do Sul, Porto Alegre, 2010.

LOPES, Maria Immacolata Vassallo. Pesquisa em comunicação: formulação de um modelo metodológico. São Paulo: Loyola, 1990.

LOPES, Maria Immacolata Vassallo. Mediação e recepção: Algumas conexões teóricas e metodológicas nos estudos latino-americanos de comunicação. MATRIZes, São Paulo, v. 8, n. 1, p. 65-80, jan./jun., 2014.

MARCONI, Marina Andrade; LAKATOS, Eva Maria. Fundamentos de metodologia científica. 6. ed. São Paulo: Atlas, 2009.

MARTÍN-BARBERO, Jesús. Dos meios às mediações: comunicação, cultura e hegemonia. 7. ed. Rio de Janeiro: UFRJ, 2013.

MARTÍN-BARBERO, Jesús; MUÑOZ, Sonia. Televisión y melodrama: géneros y lecturas de la telenovela en Colombia. Bogotá: Tercer Mundo, 1992.

MCLUHAN, Marshall. Os meios de comunicação como extensão do homem. São Paulo: Cultrix, 2007.

NATANSOHN, Graciela. 0 que há e o que falta nos estudos sobre recepção e leitura na web? E-compós, Brasília, v.10, n.3, p. 1-16, dez. 2007.

NAVARRO, Raúl Fuentes. Fontes bibliográficas da pesquisa acadêmica nos cursos de pósgraduação em comunicação no Brasil e no México: uma aproximação da análise comparativa. MATRIZes, São Paulo, n. 1, out. 2007. 
OROZCO, Guilhermo Gómez. De las mediaciones a los medios: contribuciones de la obra de Martín-Barbero al estudio de los medios y sus procesos de recepción. In: TOSCANO, Maria Cristina; REGUILLO, Rossana. Mapas nocturnos: diálogos con la obra de Jesús MartínBarbero. Santa Fé de Bogotá: Siglo del Hombre Editores, 1998.

PEREIRA, Vinícius Andrade. Tendências das tecnologias da comunicação: da escrita às mídias digitais. In: CONGRESSO BRASILEIRO DE CIÊNCIA E COMUNICAÇÃO, 24., 2002, Salvador. Anais... Salvador: Intercom, 2002.

PIENIZ, Mônica. Tecnicidade como mediação empírica: a reconfiguração da recepção de telenovela a partir do Twitter. 2013. Tese (Doutorado em Comunicação e Informação) Universidade Federal do Rio Grande do Sul, Porto Alegre, 2013.

PUTNAM, Robert David. Bowling alone: the collapse and revival of american community. New York: Simon and Schuster, 2000.

REID, Elizabeth. Electropolis: communication and community on internet relay chat. 1991. Honours thesis - University of Melbourne, Meulborne, 1991.

SANTAELLA, Maria Lucia Braga. Comunicação e pesquisa: projetos para mestrado e doutorado. São Paulo: Hacker Editores, 2001.

SANTAELLA, Maria Lucia Braga. A ecologia pluralista da comunicação: conectividade, mobilidade, ubiquidade. São Paulo: Paulus, 2010.

SCOLARI, Carlos. Hipermediaciones: elementos para una teoría de la comunicación digital interactiva. Barcelona: Editorial Gedisa, 2008.

SIGNATES, Luiz. Estudo sobre o conceito de mediação e sua validade como categoria de análise para os estudos em Comunicação. Novos Olhares, São Paulo, n. 12, 2003.

SILVA, Ronei Teodoro da. Configuração das mediações na internet: fluxo comunicacional das críticas de filmes publicadas no YouTube. 2017. Tese (Doutorado em Comunicação e Informação) - Universidade Federal do Rio Grande do Sul, Porto Alegre, 2017.

SILVERSTONE, Roger. Por que estudar a mídia? São Paulo: Loyola, 2002.

SHIRKY, Clay. Here comes everybody: how change happens when people come together. EUA: Penguin UK, 2009.

THOMPSON, John B. Ideologia e cultura moderna: teoria social crítica na era dos meios de comunicação de massa. Petrópolis: Vozes, 1995. 


\title{
Mediations analysis in interaction environments on internet researches: a methodological proposal
}

\begin{abstract}
In the last decades, several researchers have been interested in investigating reception and consumption of information phenomena present in the interactions between subjects on the Internet. However, it is possible to observe difficulties in the association of cultural issues with technological ones or, still, the necessity of an approximation between theories about culture, politics and communication to those more focused on the virtual environment. Given this scenario, we propose, in this article, a methodological approach that combines Social Network Analysis with the Mediations Map as a way of combining different methodological traditions in order to investigate an object common to both fields. This strategy was elaborated and applied in the doctoral thesis that served as the basis for this article. The goal was to understand the mediations that shape the relationships between production logics and movie criticism practices on YouTube.
\end{abstract}

\section{Keywords}

Mediations. Internet. Methodology. Communication. Interaction.

Recebido em 20/03/2018

Aceito em 23/05/2018 